\section{Thunterian Perture}

\author{
ON THE
}

\section{NATURE AND CAUSE OF OLD-AGE FNLARGE- NIENT' OF THE PROSTATL.}

$\mathbf{B Y}$

Professor KENNETH M. WALKER, M.A., M.B., F.R.C.S., LECTURER IN VENEREAL DISEASES, ST. BARTHOLOMEW'S HOSPITAL SURGEON TO OUT-PATIENTS, ROYAL NORTHERN HOSPITAI.

There are few problems in medicine that have attracted more attention or given rise to a greater diversity of opinion than the problem of the nature and cause of enlargement of the prostate. One has only to glance through medical litera: ture since the first reference to the subject by Nicola Massa, a Venctian physician of the sixtecnth century, to realize how much research has already becn expended on this subject and how little we really know concerning the genesis and pathology of the condition. In venturing, therefore, to make it the subject of my lecture on this, the second occasion that you have done me the honour of inviting me to address you, I would claim your special indulgence. Far abler investigator's thạn myself have failed to throw any fresh light on this subject. In my liumble opinion their failure has not infrequently been due to the fact that they have viewed the problem from too narrow an angle-as a surgcon, as a patho. logist, or as an anatomist, as the caso might be. For this reason I have tried to stand further back from my subject and to take as wide a view of it as possible, in the hope that where my investigation migit fail in depth of vision it would gain in breadtl. I have even iucluded in its scops a con. sideration of enlargement of the prostate occurring in animals other than man, and an investigation of its incidence amongst the various races of the world. I have done this not only because I believed it to be the best method of tackling the subject of prostatic enlargement, but also because $I$ an convinced that it is the manner in which all research should be pursued. The days of working in watertight compartments are over, and if in the future we are to continue making progress there must be a close liaison not only between medicine, surgery, and pathology, but also between these and the kindred sciences of comparative anatomy, anthropology, and veterinary surgery.

The Frequency of Prostatic Eulargement.

Before going further into the subject it is advisable to lay down clearly that I propose to limit $\mathrm{my}$ inquiries to tho in restigation of only one type of enlargement of the prostate - the glandular, or what is commonly known as the adens. matous piostate. Of inflammatory enlargements of the fibrous type, and of carcinoma, I shall say little or nothing.

The first point to strike anyone who conscientiously examines prostates, whether his examination be made in the post-mortem room or in the out-patients' department, is the frequency with which some degree of enlargement occurs after the age of 50 lias been reached. 'This, of cour'se, is more obvious in the post-mortem room than in the outpatients' department, for it is only by means of such special examinations as cystoscopy and posterior urethroscopy that inany of the lesser degrees of enlargement can be diagnosed during life. As an indication of the commonness with which this increase in tho size of the prostate occurs after the age of 50 I have produced a curve which represents the size of the prostate in the various decades of tife. -(Wig. 1.) This curve has been constructed mainly from data supplied by Lowsley in his extensive work on the size and form of the prostate from birth to old age. It will be seen from the curve that the maximum size is reached somervhere about the age of 60 . After this period there is a slow diminution

* Delivered before the Royal College of Surgeons of England on February 3rd, 1922. in size with the adrent of senility. It may therefore be accepted that some degree of enlargement after the age of 50 is the rule rather than the exception. This fact lias been emphasized by sucli writers as Sir Astley Cooper, and notably by Sir Benjamin Brodie, who wrote:

" When the hair becomes grey and thin, when atberomatous deposits invade the arterial walls, when there is formed a white zone about the cornea, at the same time ordinarily, I dare say invariably, the prostate increases in volume."

However, although this is so, it must be remembered that only a percentage of those whose prostates show enlarge ment suffer any disability therefrom. There is no direct relation between the degree of enlargement and the severity of the symptoms. It is indeed by - no means rare to find in the post-mortem room a prostate. weighing as much as 40 grams, which lias not produced any symptoms during life.

What is still more interesting is the fact that enlargement of the prostate during the latter part of life is by no means a prerogative of the human race. Of its incidence amongst domestic animals I cannot yet speak with any dègrec of certainty, owing to the difficulty I have encountered in obtaining specimens of uncastrated animals dying of 'old ago. Amongst dogs, at any rate, it is extremely common, and, as old dogs are easily obtained, much of my work has been done on that animal. However, from the material which has becn put at my disposal by the courtesy of the Veterinary College and the Zoological Society, I believe there to be a general tendency throughout the whole animal world towards eulargements of the secondary sexual glands in old age.

The Nature of the Enlarge. ment.

Not only are we in com plete ignorance as to the causes underlying enlargement of the prostate, but we are in doubt as to the nature of the enlargement itself. Is it a hyperplasia following previous inflam. mation, or is it in the nature of a neoplasm? The most convenient method of dealing with the subject will be to pass uuder revier the theories of cnlargement which liave at various times been put forward, and to see whether they fit in with ascertained? facts. These theories may bo considered undor three headings:

1. The inflammatory theory.

2. Neoplasms.

3. Degeneration theories.

The Inflammatory Theory.

The possibility of prostatic enlargement being due to an inflammatory process was suggested by De Sault as long ago as 1813. Since theu the theory lias been upheld by a great number of authcrities, and especially by Rotschild and Ciechanowsky.

This latter observer maintained that no true increase of gland tissue occurred with enlargement of the prostate. The increase he regarded as only apparent, and due to dilatation of the glands. According to Ciechanowsky, the dilatation *.. was the result of blockage of the prostatic ducts following inflammation in the surrounding stroma. The obstrinction of the ducts resulted in the accumulation of secretion in the acini an'd their gradual dilatation. The chief cause of enlargement of the prostate would (according to this theory) be previous attacks of inflam. would (according to this theory) be p"evious attacks of inflam.
mation, and particularly of inflammation in the stroma surrounding mation, and particu

This inflammatory tiscory has received so much support that no apologies need be offered for dealing with it at some length. Infection is one of the commonest causes of cell proliferation that we know, aud the urethra and the prostate are particularly exposed to infective processes. Yet in spite of the seductive nature of the theory, offering, as it does, a simple and easily acceptable explanation of enlargement, I am convinced that it is insufficient to explain the type of prostate under present consideration. IIy reasons for refusing to accept the inflammatory theory, as put forward by Ciechanowsky, are as follows:

1. That as a rule signs of inflammatory reaction are absent in sections of enlarged prostate. It is true that occasionally a round cell infiltration is to be found, but I believe this to be a secondary 
condition and one that is dependent on a superimposed sepsis of the urinary tract. When the frequency with which sepsis follows prostatic enlargement is remembered the occasional appearance of a round-cell infiltration in such sections is not surprising.

2. That I have never succeeded in demonstrating organisms in microscopic sections of enlarged prostate. These negative results are in conformity with those obtained by Dudgeon and Cuthbert Wallace. It is true that these observers by means of cultural methods succeeded in obtaining evidence of organisms in enlarged prostates, but the low grade pathogenicity of the organisms obtained was strongly against their being responsible for the condition of enlargement.

3. If enlargement is due to dilatation of existing glands rather than to proliferation, a direct relationship should exist between the size of the prostate and the degree of glandular dilatation that has taken place. "Ex pede Herculem." No such relation exists. In other words, it is impossible for a person who examines a microscopic section to state whether it comes from a very large oi only a moderate-sized prostate. Dilatation, moreover, of glands is not infrequently found in old prostates showing no enlargement whatever.

4. No clinical relationship can be established between enlargement of the prostate and previous urinary infections, whethe gonococcal or otherwise. As will be subsequently shown, enlarge ment is particularly rare in the very races that suffer most from veuereal disease.

\section{The Adenoma Theory.}

The adenoma theory has been supported by Socin, Coln heim, Rindfleisch, Cuthbert Wallace, Velpeau and the French school of Pathology. It is probably the view that is most commonly held at the present time, but the arguments against it are very strong. While I agree that the type of enlargement we are considering may supply conditions favourable to the formation of definite neoplasms, I am con vinced that the enlargement itself is not neoplastic in origin. The arguments against the neoplastic theory are as follows:

1. In order to explain the condition found in enlargement of the prostate we should have to postulate the appearance of multiple adenomata not only in the prostate itself but in the peri-urethral, subcervical, and in certain cases the subtrigonal glands, for, as we shall subsequently see, enlargement of the prostate is not an isolated phenomenon, but is associated with widespread changes in the genital tract.

2. Adenomata are not common at the age at which prostatic enlargement occurs.

3. If we examine a microscopic section we find that the newly formed glandular tissue reprociuces the original prostatic tubules with extreme fidelity. They are often indistinguishable from normal prostatic glands, and, as has been shown by. Herring, they are provided with well formed ducts. They also secrete a fluid similar to prostatic flnid, but containing more fat. The tissue of tumour, on the other hand, is almost invariably atypical, and with rare exceptions it does not develop the physiological properties of the organ in which it develops.

\section{Theories of Degeneration.}

On a priori grounds there is much to be said in favour of a theory that regards enlargement of the prostate as a degenera. tive process overtaking an organ that has passed its period of full functional activity. Although a man of 55 may be regarded as comparatively young, yet from the point of view of his reproductive system he is old. It is true that active spermatogenesis may be seen in the seminiferous tubules of a nonagenarian and that the sexual life of the male has no abrupt termination. The menopause in his case is so gradual in its onset as to be almost imperceptible. Nevertheless a decline in sexual activity occurs and the genital tract of a man of 55 bears unmistakable signs of involution. Launois was one of the first to suggest that enlargement of the prostate is but a part of a degenerative fibrosis taking place throughout the whole urinary apparatus, kidney, bladder, etc. The cause underlying this degeneration he considered to be arterio-sclerosis. This view was supported by Guyon and many others. However, although Launo:s was undoubtedly right in drawing attention to the fact that prostatic enlarge. ment is a part of a general change, it cannct be said that subsequent observations, including my own, have shown that this change is necessarily associated with arterio-sclerosis. Ciechanowsky, Casper, and Motz have all failed to find evidence that arterio-sclerosis is the cause underlying prostatic enlargement, and in my own series of cases not more than 10 per cent. showed arterial thickening. When the age of these cases is taken into consideration the occasional existence of arterio-sclerosis is not surprising.
Other observer's have suggested that the prostatic condition is secondary to changes in the testes rather than to the presence of an arterial lesion. The relation between the testis and the prostate is a very close one, especially during the first half of life, and the theory is a plausible one. In . order to test it I have made a careful examination of the testes associated with enlargement of the prostate, both as regards their relative weights and their histological appear ance. I have entirely failed to establish any relation between the weiglit and naked-eye appearance of the testes and the size of the prostate. Microscopic examination of testes shows, however, the existence of changes that are undoubtedly degenerative in nature. The basement membrane of the tubules is thickened and the interstitial cells of Leydig are scanty, and in some cases obviously degenerating. In sections stained with Scharlach $R$. the cells of the tubules show the presence of numerous coarse granules. That these granules are due to the formation of fat in cells undergoing degeneration can be shown by suitable methods of staining and by the use of crossed prisms. However, although signs of degeneration of the tubules are undoubtedly present, spermatogenesis is by no means arrested.

In eight out of eleven prostatic cases I found active spermatogenesis to be present. Of the three cases in which it was absen two had suffered from malignant prostates, and, as Mott has shown, spermatogenesis is in any case absent in cases of malignan disease. A point of especial interest in connexion with these sections was the fact that the degenerative processes were distinctly patchy in distribution-that is to say, one tubule would show obvious changes and cessation of spermatogenesis, whilst another would appear to be fairly normal.

As a control the testes of men of equal age, but without enlargement of the prostate, were examined. Similar changes to the above were found in these controls.

It must therefore be concluded that the alteration in the testes that are associated with enlargement of the prostate do not differ in kind (although they may be slightly greater in degree) from the changes that normally take place in the testis at the end of active sexual life.

Having reviewed the theories that have been advanced to explain the condition, it will next be advisab!e to malse a brief survey of some of the distinguisising features of prostatic enlargement, including its macroscopic and microscopic appearance. We shall then be in a position to see whether there is any other theory which offers a more satis. factory explanation of the condition.

The Site of the Enlargement.

The first point to be considered is the precise situation in which the increase in size occurs. What part of the prostate is most commonly affected? The fact that so many of our statistics on the subject have been drawn from surgical sources has led to an exaggerated idea of the rôle played by the middle lobe in this matter. Increase in the size of this lobe is, of course, almost invariably productive of symptoms, and it is on this account rather than becanse the middle lobe has any monopoly in enlargement that such emphasis has been laid on it. By far the commonest form of enlargement (over 70 per cent. of my cases) is one which involves lateral and middle lobes alike. Indeed, there is only one portion of the prostate which does not take part in enlargement, and that is the posterior lobe. So fer are the exceptions to this rule that I have been tempted to believe that the prostate (concerning whose functions we know so little) is in reality a. composite gland, the posterior lobe of which differs, not only in histological structure but also in its function, from the rest of the gland. At any rate, there is sufficient ground for the belief that the posterior lobe has an individuality of its own, and one of the points of difference between it and its fellows is the fact that although it is not infrequently the starting point of a carcinoma it scarcely ever talres part in a non-malignant enlargement.

Motz and Perearnau have advanced the view that what has been termed enlargement of the prostate is in reality not an enlargement of the prostate proper but rather of the sub. mucous glands. The situation of the glands to which these authors have accorded so important a rôle is best seen in a section through the posterior urethra and bladder neck somewhere about the fifth foetal month. Fig. 2 is from a dimgram of Lowsley's, and shows that the glands are arratfyed in three groups: (1) The urethral (Albarran's glands); (2) the subcervical; and (3) subtrigonal. The names given to the different groups sufficiently describe their situation. There is one point; however; that is worthy of emphasis, and that is 
the fact that the subcervical group of glands is separated from the prestate proper by the interposition of the bladder splincter. The fact that the subcervical glands lie internal to the sphincter gives support to the view that they rather than the prostate play the chief part in obstructions in the neighbourhood of the vesical neck, and in intra. vesical projections (specimen). However, whilst readily admitting that these glands, rather than the prostate itself, are in many cases the cause of an obstruction, Motz and Perearnau have, in my opinion, gone too far in denying all responsibility to the prostate. The truth, as is so often the case in arguments, scientific or otherwise, would appear to be that both statements are correct. Some cases of en. largement are mainly prostatic, whilst others are mainly stibmucous.- It is difficult, if not impossible, to estimate the percentage of cases in which the obstruction is mainly submucous and that in which it is chiefly prostatic. However, as a rough indication of the frequency with which alterations in the submucous glands are encountered we have Lowsley's statement that in men over 30 Albarran's group of glands are enlarged in 25 per cent. of cases and the subcervical group in 22.8 per cent. Similarly, J. R. Caulk, as the result of the examination of 485 cases of clinical obstruction, found enlargement of Albarran's glands in 97 (20 per cent).

\section{Prostatic Enlargement a Part of a Condition Affecting} the Whole Genital 'Tract.

Already we have accumulated sufficient evidence to justify the statement that enlargernent of the prostate is not an isolated phenomenon, but is associated with changes in other portions of the genital tract. These changes (which, at any rate in the case of testis, are definitely degenerative in nature) are found in the testis, the prostate proper, the peri-urethral, subcervical, and subtrigonal glands. 'There is also evidence that the vesiculae seminales may be implicated. In a great many cases they are found to bo enlarged and thickened. According to Lowsley, this occurs in 32 per cent. of men over the age of 30 . In certain instances the dilatation and thickening of the vesicles may be indirectly due to pressure on the ejaculatory ducts, but in others the change is a part of the degenerative process affecting the whole genital tract.

\section{Section of Enlarged Prostate.}

The following are the naked eye and microscopical appearances:

Naked Eye Appearance.-A section through an enlarged prostate reveals:the presence of a number of small round opaque areas of a colour that varies from white to a pale yellow. These areas are scattered throughout the substance of the gland. By the advocates of the neoplasm theory they have been regarded as adenontata. They are surrounded by a capsule of translucent normal prostatio tissue, from which they can be enucleated with comparative ease. In certain cases these primary areas are subdivided into secondary smaller ones. Similar areas are to be seen in the enlarged prostate of a dog.

Microscopic Appearance.-A microscopic examination shows that the opaque masses or nodules described above are formed of glandular tissue. In a single section may of ten be seen different phases in their development. This is especially the case if the dog pe selected for the purpose of their study.

At an early stage in the formation of one of these masses there is an active proliferation of the endothelial lining of a group of glands. The proliferation is mainly directed to the formation of a large number of intra-acinous growths, which become more an more luxuriant as time goes on. As a result of the enlargemen occurring in these central glands the surrounding tissues with their gands become disposed concentrically around the area of proliferation so as to form a capsule. The formation of intraacinous growths in time becomes so luxuriant that a section through one of these areas of proliferation resembles nothing so much as a section through a papilliferous ovarian cyst: In frozen much as a section through a papilliferous ovarian cyst: In frozen seen that in certain areas these proliferated glands are undergoing marked fatty degeneration. The microscopic appearances in the human prostate are similar to the above, although - less striking There exists the same tendency to the formation of intra-afinous growths, and there are the same patches of fatty degeneration.

Although there might seem to be little in common between the above and the changes that have previously been described as occurring in the testes associated with the enlargement, the similarity is greater than would at first sight appear. In both testis and prostate we have a degenerative process that picks out certain tubules whilst it leaves others more or less intact. In the gland cells of either organ we note the same structural alterations-namely, an enormous increase in the size and number of granules that take on a red stain with Scharlach $R$. In both instances this fatty degeneration is patchy in its distribution throughout the organ and is associated with an increase in the interstitial fibrous tissue. The chief difference lies in the fact that whereas the tubules of the prostate have undergone a previous proliferation, those of the testis have not.

\section{The Cause of Enlargement.}

An enlarged prostate is, therefore, according to this view, to be regarded as a prostate that has undergone a form of degeneration which, for the sake of convenience, we may term fibro-epithelial. The condition may be considered in the light of an accident that has occurred during the period of involution of the genital tract. If we look for an analogy to this in the case of the female we may find one in the some. what obscure condition known as a sero-cystic disease of the breast. The breast, like the prostate, is one of the secondary sexual glands. It is in intimate association with the ovary, just as the prostate is with the testis. Finally, the breast shares with the prostate the same tendency to develop lesions during the period of sexual decline. When we examine a microscopic section of a breast that has become enlarged as the result of sero-cystic disease, we find that it presents a very close similarity to that of an enlarged prostate. We find the same formation of intra-acinous growths as the result of epithelial proliferation. There is the same tendency to dilatation of the acini, and an equal absence of round-celled infiltration, or of other signs of in. flammation. Moreover, the changes in the breast show the same patchy distribution that we have seen to be characteristic of the prostatic con dition, one group of glands being markedly affected whilst another remains free. The most obvious difference between the prostatic and the breast lesions is the presence of fatty degeneration in the former case and its absence in the latter.

The difficult question now arises as to what are the causes that determine the onset of fibro-epithelial degeneration. Why should one prostate undergo an enormous enlargement whilst another to all intents and purposes escapes? We have seen that infection alone fails to account for the condition, although it may possibly act as a contributory cause. Is there any reason to suppose that any of the other causes that have been put forward at various times exert any real influence? It has been suggested that congestion may determine the onset of enlargement. We know that chronic engorgement may cause hyperplasia, and there are reasons for believing that the prostate is particularly prone to con: gestion. The frequency with which a thrombosis of the plexus of Santorini is found in the prostate at necropsy is sufficient evidence of the liability of this organ to venous stasis. But although there exists an antecedent probability that venous congestion may be a contributory cause, it is unlikely that it is of more than secondary importance. Other possible explanations must therefore be examined.

The Relation of the Prostate to the Endocrine System.

The intimate relationship of the prostate to the interstitial cells of Leydig in the testis is well known. Through Leydig cells the prostate becomes linked with the other endocrine glands, and notably with the suprarenals and the pituitary. The relationship between the prostate and the pituitary has indeed been directly demonstrated by Coetsch, who found that, in feeding experiments upon young bypo. physectomized rats, anterior lobe stimulated the growth of the prostate whilst posterior did not. But in addition to this well-established connexion between the prostate and the endocrine system, a claim has been advanced by certain observers that the prostate itself is responsible for the elaboration of an internal secretion. The evidence in favour of this, although suggestive, is very far from being conclusive, and is cliefly based on the work of Macht. 
Macht fed tadpoles on prostatic fluid and demonstrated that it hastened differentiation and metamorphosis, but to a less extent than did thyroid extract. He also found that injections of the extract provoled contraction of the genitourinary organs both in the male and female (that is, uterus, bladder, ureters, etc.). Aitention has, moreover, frequently been called to the fact that mental symptoms are particu. larly proue to develop after prostatectomy. Maclit, however, as the result of a series of ingenious experiments on prostatectomized rats, showed that in the case of these animals cerebration was unimpaired by prostatectomy. The mental symptoms following prostatectomy should, therefore, in the light of what we have found, be correlated with the degenerative processes that have taken place in the testes, rather than with any removal of prostatic secretion.

My own observations, as far as they go, indicate that injections of extract of prostate in the human being do not produce any response in the way of alteration of blood pressure, pulse, respiration, etc. I have used both an autolysit and a commercial preparation of prostatic extract for this purpose and have never obtained a reaction that could be appreciated clinically. Incidentally I may mention that I lave found that prostatic extract, when employed as a therapeutic measure, is occasionally of use during the early phases of enlargement, but of little benefit in the later.

As a final piece of evidence in favour of the prostate furnishing an internal secretion is the case reported by Doré, in whicli prostatectomy was followed by a marked hypertrophy of the breasts.

Apart from the above considerations the close dependence of the prostate on the ductless glands during its period of development affords sufficient ground for considering carefully the possibility that enlargement may be associated with some change in the endocrine system. The menopause in the female is generally accompanied by a temporary loss of endocrine balance, and it is not improbable that a similar state of affairs may arise during the period of sexual decline in the male. For this reason I have considered it advisable to examine the interstitial cells of the testis, the suprarenal capsules, and the pituitary in cases of prostatic enlargement. The necessity for examining the interstitial cells of Leydig had, indeed, long been apparent, and remembering the tendency of " prostatics" to exhibit exaggerated sexual desire, the possibility had occurred to me that enlargement and sex hyperaesthesia might both depend on an increase in Leydig cells. That this is not the case has already been shown in the section dealing with changes in the testis. I found that Leydig cells were diminished rather than increased in cases of prostatic enlargement. So far I have not been able to demonstrate any alteration in structure in either the supra. renal or the pituitary, but as the histology of the endocrine glands is notoriously difficult on account of early post-mortem changes I would prefer at the present to make no further statement an the subject. The condition of the endocrine glands in cases of prostatic enlargement offers a fruitful field for research, not only by means of histological methods, but still more by an investigation of basal metabolism and a determination of the respiratory quotient.

\section{Racial Distribution of Enlargement.}

In the hope that thereby some light might be thrown on its etiology, I have obtained what information I could on the incidence of prostatic enlargement amongst the various races of the world. In trying to arrive at an estimate of its frequency it must always be borne in mind that enlargement is a disease of old age, and that where old men are rare enlargement will be rare also. This undoubtedly explains to some extent the rarity with which prostatic obstruction is encountered amongst certain African races. It also makes the interpretation of hospital statistics difficult, and prevents the giving of anything more than a general impression of the frequency of the condition.

'The following summary has been prepared from the answers' received to $\mathrm{my}$ questionnaire inquiring into the incidence of the condition in the various countries of the world.

India-Prostatic enlargement is fairly common, but less so than in England. In an out-patients' department dealing with approximately 1,000 new male cases per annum, some 30 cases of prostatic mately 1,000 new male cases per annum, some 30 cases of prostatic amongst Mohammedans than Hindus. It is found more frequently amongst the well-to-do than the hospital class. As in other countries where the individual reaches sexual maturity at an early age the onset of symptoms from enlargement is earlier thau in England.

Japan.-Prostatic enlargement is very rare. Dr. Matsumoto reports that in the records of the out-patients' department of the special Hospital for Urinary Diseases at the University of Kyoto there is an average of four cases of enlarged prostate per annum, although the total attendances run into several thousands. Professor Hayami, of the same university, has never encountered the condition on the dissecting table. Japanese literature on the subject is very scanty.

China.-Very rare. Dr. Koch, of the Government Hospital at Hong Kong, states that during the last fourteen years no case of enlargement has been seen, although the yearly averace of inpatients is 4,000 and of out-patients 25,000 . Similarly, in the Canton Hospital records for the years 1915 1916, and 1919 there are three entries of prostatic enlargement, glthough during the same period as many as 156 cases of vesical calculi are recorded. During the ten years 1910-1919, 13,761 operations were performed in this hospital, of which 6 were prostatectomies.

Egypt.-Fairly common, but less common than in England. At the Kasr-el-Ainy Hospital, Cairo, there were 17 cases of prostatic enlargement in 1921 out of a total of 8,472 male in-patients. This appears to constitute an average for the last ten years. All except one of these cases were amongst Egyptians. The actual incidenc of the trouble is higher than the above figures indicate, as patients do not usually report until urgent symptoms supervene. It appears to be common amongst the well-to-do classes. In Upper Egypt and the Sudan enlargement is much rarer. It is interesting to note that in the same region hypertrophy of the breast in the male is comparatively conmon.

South Africa.-An inquiry amongst medical men practising amongst natives has elicited the unanimous opinion that enlarge ment is extremely rare amongst the natives of South Africa. It must, however, be remembered that few natives live beyond the age of 50 .

South America.-Common to those of European stock living in large cities. Incidence amongst aborigines unascertained.

North America.-Incidence in white population apparently as great as in England. The majority of American writers agree that the condition is rare amongst the negroes of the States, the only statement to the contrary being made by Matas. C. H. Day estimates the ratio of incidence amongst whites to that amongst negroes to be as 7 to 3 . If this is only approximately correct the incidence amongst the negroes of North A merics would appear 10 be greater than that for the original African stock from which they came.

Incomplete as this attempt to discover the incidence of prostatic enlargement may be, it is at any rate sufficient to justify the foliowing deductions:

1. That enlargement of the prostate is a condition having a definite distribution that is anthropological rather than geographical in character. Whereas the condition is common in the Circassian race generally, both in Europe and in the New World, it is somewhat less frequently found amongst those of Semitic and Arab stock, and amongst the inhabitants of India. Amongst Mongols and Negroes it is extremely rare.

2. That enlargement can have nothing to do with the causes that have at various times been suggested as determining its incidence-that is, previous attacks of gonorrhoea, sexual excesses, masturbation, etc.-for the races that are more or less immune from enlargement are the very races in which these supposed causes are most in evidence. Generally speaking, enlargement is commoner amongst meat eaters and those leading the sedentary lives of cities than amongst the vegetarians and frugal livers.

\section{Conclusions.}

1. It is impossible to explain enlargement of the prostate by any theory of chronic inflammation alone.

2. Although enlargement may reproduce conditions favourable to the development of a neoplasm, the enlargement itself does not come into the category of true tumours.

3. The condition is in the nature of a fibro-epithelial degeneration which finds its analogy in the female in serocystic disease of the breast.

4. This degeneration may be regarded as an accident occurring during the progress of involution of the genital tract.

5. The cause that determines the onset of the condition is unknown, although it is not improbably connected with a loss of endocrine balance occurring during this period.

6. Prostatic enlargement shows a definite distribution that is anthropological rather than geographical in character. It very rarely occurs amongst Mongolians and Negroes.

My thanks are due to so many for their assistance in providing me with material and facilities for the above research that it is impossible to mention them all specifically by name. I wish, however, to express my special obligation to Professor Reynolds 
F.R.C.V.S., and above all to Sir Frederick Mott, F.R.S., and the authorities of the Mandsley Hospital for allowing me to work in their well-equipped laboratories.

\section{Bibliography.}

Lowsley, O. S.: Surg., Gyn., and Obstet., 1915, p. 183; Annals of Surgery, 1915, 716; Med. Record, 1916, xc, 3-10.

Cooper, Astley: Lectures on Genito-Urinary Organs, 1824.

Squier: Med. News, 1901, 78

De Sault: Oeuvres Clin.. 1813, 3, p. 238.

Ciechanowsky: Anatomical Research on Prostatic Hyperlrophy (translated by Green, 1903).

allace, Cuthbert: Prostatic Enlargement.

ocin: Handbuch der Chirurgie. 1871-75, 111, 8.

Patheine Pathologie, 1877.

Velpeau : J,econs Orales de Clinic de Chirurgie, 18t1.

Herring, H. '1.: BRITIs MEDICAL JodRNAL, October 29th, 1904.

Launois: Thèse de Paris, 1885.

Casper: Virchcw's Archiv, J Xxvi, 139

Mott. Sir Frederick: BRITISH MEDICAL JodRNAL, 1919.

Motz and Perearnau : Ann. de Mal. de Org. Génito-Urinzire, 1905.

Caulk. G. J., and Latimer, M. J.: American Medicine, 1919, p. 899.

Serralach and Pares: Contptes Rendus Soc. Biol., 1907, 1xiii, 790.

Macht, David : Journ. of Urolrgy, April, 1920: January, 1921.

Macht and Matsumoto: Journ. of Urology, June, 1920.

Doré: Journ. d'Urologie, vol. $\mathrm{x}$.

Matas: Transactions Amer. Surgical Association, xiv.

Day, G. H.: Journ. of Urology, January, 1921.

\section{METABOLISM OF CHILDREN UNDERGOING OPEN-AIR TREATMENT, HELIO'THERAPY AND BALNEOTHERAPY.}

LEONARD HILL, M.B., AND J. ARGYLL CAMPBELL,
F.R.S.,
(FROM., D.SC.

With the Co-operation of

Sir HENRY GAUVAIN, M.A., M.D., M.C.

Is consideration of the beneficial effect of heliotherapy in the treatment of tuberculosis attention has been turned almost entirely to the influence of the ultra-violet rays, which do not penetrate more than $0.1 \mathrm{~mm}$. (F. E. Barnard), being absorbed by the surface film of the skin; and (perhaps) more justly to the luminous rays, which, in part, penetrate and are absorbed by the blood and deeper tissues. Other factors of great importance must also be taken into account-namely, the effect of the cooling power of the open air on the exposed body in stimulating muscle tone and body metabolism; the effect of breathing cool air with low vapour tension on pro. moting evaporation from the respiratory membrane, ${ }^{1}$ and so enhancing the outflow of secretion from it and the flow of lymph and arterial blood through it; the effect of cool air in promoting evaporation from and flow of lymph through sores and discharging sinuses; the effect of sunshine in promoting such evaporation and flow, and in warming diseased parts exposed to it. In this paper we propose to consider the effect on body metabolism.

In published results ${ }^{2}$ it was shown that body metabolism or heat production of healthy adults was raised by sitting quietly out of doers in the shade for half an bour on an ordinary winter's day, and that shivering was not necessary to raise metabolism. We found that a cooling power between 15 and 20, as measured by Hill's dry kata.thermometer, gave the proper conditions for avoiding shivering for our subjects, who wore the same clothes as indoors.

To continue our observations on the effect of open air, and at the same time to investigate that of heliotherapy on body metabolism, we carried out a number of experiments at Lord Mayor Treloar's Hospital at Alton, and Hayling Island, Hampshire, during the past summer. In the present paper we record these results.

The conditions at this hospital were particularly suitable, our subjects being children with surgical tuberculosis, treated, among other methods, by open air and heliotherapy. After a course of skilful training the children are able to lie naked in the open air for many hours under atmospheric conditions which would soon make an ordinary heaithy individual shiver and uncomfortable unless wearing his ordinary clothes. The process by which the children are inured to exposure is a gradual one and takes a longer time in some cases than in others." Sir Henry Gauvain, ${ }^{3}$ the medical superintendent, has described the method as employed at Alton.

Methods.

We used the Douglas-Haldane method of indirect calorimetry, following the directions given by Cathcart; ${ }^{4}$ in this method, which is recognized to be an accurate one, both $\mathrm{O}_{2}$ and $\mathrm{CO}_{2}$ are estimated in the expired air.

The children under observation were of an age -8 to 16 years-of understanding, and met the conditions of experiment willingly. After a few preliminary trials with the mouthpiece, the process of taling a sample of expired air concerned them little. One factor which helped us con. siderably was that our subjects, being hip or spine cases, were fixed in splints in bed. Movement, except of the head and arms, was practically impossible. We took care to exclude movement of the head and arms for the usual period before taking the sample.

Breakfast was taken at 6 a.m., a glass of milk at 8.30 a.m., dinner at 12 noon, tea at 4 p.m., and supper at 7 p.m. (summer time). In the case of observations made before breakfast, breakfast was taken at 8.30 a.m. Observations after break. fast were made between 10 a.m. and 12 noon; those after dinner between 2 p.m. and 4 p.m.

Records of dry and wet bulb air temperatures, of dry and wet kata-thermometer cooling powers, and of black fur surface tomperatures were taken to give indications of the atmospheric conditions under which the observations were made. The last give a measure of the radiant energy of the sun. Records of cheel surface and axillary body tempera. tures and of pulse rates were also taken. Wedid not employ subjects who showed an abnormal body temperature. Only one or two of our cases showed a broken skin, and these lesions were sinuses or ulcers of a minor degree.

For comparison, we have used the figures for calories per diem given in Benedict and Talbot's ${ }^{5}$ standards for children of the same weight as ours; these are well known basal standards. Strictily speaking, the only figures of our results that may be compared with these basal standards are those we obtained from our subjects in the post-absorptive statethat is, before brealfast. Nevertheless for comparing one set of our figures with another set of our fignres obtained under similar conditions in regard to the taking of food, we have taken the liberty of using these standards, and noted what difference each set of our results showed from the standard for children of the same weight as ours. This seemed to be the best method for comparing our results. We have also calculated the heat production per unit of body surface, using both Du Bois's and Benedict and Talbot's formulae for calculating the surface and reaching the same conclusions from the use of each.

Results obtained from Children who had been Treatcd for many Months vith Open Air and Heliotherapy.

Our first experiments were done on children who had been under treatment for many months. Some of them had pigmented very well under the influence of the sun-that is to say, they had not blistered, but bronzed. Others, who did not pigment well, easily blistered, and, not tolerating much exposure to sun, were kept more in the shade. All the children on an ordinary summer's day wore only loin-slips, and paid no attention to the fact that they were so much exposed to the open air; there was no evidence of shivering.

Sir Henry Gauvain states that the children who do not pigment well are slower in progress. We noted that the children who pigmented well were usually of better weight than those who did not pigment well, but the average difference in metabolism at Alton was negligible after due allowance was made for difference in weight. From this we conclude that heliotherapy was not so much responsible for the rise in metabolism observed as was the open air, since those who pigmented well received much more heliotherapy than those who did not pigment well.

We should like to emphasize here that we were not dealing with the cure of the disease but with the metabolism alone. While many clinicians hold the view that heliotherapy is greatly concerned with the arrest of the disease, the different factors at work have not so far been analysed.

To return to our results: Table I shows the figures obtained from those who pigmented well, and Table II ghows the figures from those who did not pigment well. The Alton figures may be compared. Taking both Table I and Table II together the average increase of our figures before brealffast above the standard figures for the same weight was about 40 per cent., whereas after breakfast and after dinner the average increase over the standard was about 50 per cent. The out-of-door cooling power and its effect on metabolism vary, but we may conclude that the average effect of tho lrospital food in our observations was not more than 10 per cent. Du Bois found the basal metabolism increased only 